\title{
Developing a hierarchy-free inventory of learning strategies: BLILS (Banja Luka Inventory of Learning Strategies)
}

\author{
Siniša Lakić, Milana Damjenić, \& Sandra Grahovac
}

\begin{abstract}
The review of expert literature shows that there are a few psychometrically validated and globally used inventories of learning strategies. Nevertheless, there are several issues related to their use. First, in these operationalizations the focus is on the higher hierarchical levels within the proposed learning strategies structure; the contribution of individual learning strategies to successful learning is rarely analyzed on its own. Furthermore, the authors of extant inventories treat the phenomena from the reflective measurement perspective, although - as we argue - such approach is not compelling neither from a psychometric nor from a substantive viewpoint. Finally, some of these instruments fail to incorporate some contemporary learning techniques, which were promoted thanks to the development of digital technologies (e.g. using flash-cards on digital media, participating in MOOCs) or which were massively popularized relatively recently (e.g. mind-maps, speed reading). Therefore, we aimed to develop a comprehensive inventory of relevant learning strategies used in secondary education and to test its criterion validity by correlating it with GPA. Further, we wanted to empirically compare the predictiveness of the usual factor-level scoring against the item-level scoring. Based on the literature review and a pilot study we conducted, we identified 40 learning strategies (affective and motivational aspects were not included). Each learning strategy was represented with a single item, with participants responding on a five-level scale dependent on the frequency of the use. The sample consisted of 402 high-school students (50.2\% females). In line with our hypotheses, the results indicate that imposing a factor structure is not only theoretically questionable, but it also diminishes the instrument's criterion validity when compared to item-level analysis which was controlled for potential overfitting. We discuss why it is important to turn focus to lowerlevel assessment of learning behaviors and why psychologists should abandon strict adherence to the reflective approach when developing measures.
\end{abstract}


Keywords: learning strategies, academic performance, high-school students. 
Through available meta-analysis (Crede \& Kuncel, 2008; Credé \& Phillips, 2011; de Boer, Donker-Bergstra, \& Kostons, 2012; Richardson, Abraham, \& Bond, 2012) we now have enough evidence that the use of particular learning strategies - purposefullyinitiated learner behaviors which facilitate learning (derived from de Boer, DonkerBergstra \& Kostons, 2012) - has an effect on educational achievement. Although the estimated parameters have been only small to moderate in magnitude, due to the importance of education and its influence on global economy and well-being of the community, this finding is immensely relevant. Namely, the finding provides an empirical foothold for the practitioners who can campaign for teaching effective learning strategies and deliver such programs in practice. Obviously, one of the first practical steps for those activities is getting an insight into the use of effective and ineffective learning strategies through administering an adequate instrument to the target learners.

Indeed, a number of inventories of learning strategies and related concepts have been developed and used globally. Some of the best known ${ }^{1}$ are: MSLQ (Motivated Strategies for Learning Questionnaire; Pintrich, Smith, Garcia, \& McKeachie, 1991), ILS (the Inventory of Learning Styles; Vermunt, 1994), LASSI (Learning and Study Strategies Inventory; Weinstein, Schulte, \& Palmer, 1987; Weinstein, Palmer, \& Schulte, 2002), RSPQ-2F (The revised two-factor Study Process Questionnaire; Biggs, Kember, \& Leung, 2001). Among these, the most cited is the MSLQ, whose user manual was cited 3456 times according to the Google Scholar on February 28, 2018. This questionnaire comprises 31 items targeting three broad motivational areas of learning (value, expectancy, and affect) assessed via six subscales and 50 items targeting three broad learning strategies areas (cognitive, metacognitive, and resource management) assessed via additional nine subscales (Pintrich, Smith, Garcia, \& McKeachie, 1993).

Aside from being the most popular inventory of learning strategies, the MSLQ is also a paradigmatic instrument when it comes to the procedure of the development of the typical inventory of learning strategies. As was the case with other mentioned

\footnotetext{
${ }^{1}$ Schellings (2011) provides an exhaustive list of 21 relevant instruments.
} 
instruments, the authors first hypothesized a theoretical hierarchical ${ }^{2}$ structure with a number of higher-order concepts (e.g. Elaboration, Critical thinking). Each concept was represented with several indicators which are operationalized by individual items (two examples for Elaboration: "When I study for this class, I pull together information from different sources, such as lectures, readings and discussions." and "I try to relate ideas in this subject to those in other courses whenever possible."). In the next step, factor analysis was used to explore and refine the latent structure upon which measures of internal consistencies were presented as a final evidence of the appropriateness of the scales. When it comes to criterion validity, the analyses were focused on the level of subscales, although the user manual (Pintrich, Smith, Garcia, \& McKeachie, 1991) provides readers with correlations of individual items with final grades ${ }^{3}$.

The latent variable modeling approach was also used in two recent papers explicitly revisiting the MSLQ. Based on the fit indices obtained from a confirmatory factor analysis, Hilpert and colleagues (Hilpert, Stempien, van der Hoeven Kraft, \& Husman, 2013) concluded that out of 15 scales only three scales should be kept with six indicators each, and thus, one should discard all cognitive learning strategies from the instrument (e.g. Rehearsal, Organization, Elaboration, Critical thinking). On the other hand, Dunn and colleagues (Dunn, Lo, Mulvenon, \& Sutcliffe, 2012) concentrated on analyzing only two scales - Metacognition and Effort regulation - through both exploratory and confirmatory approach. They concluded that out of 16 items one should discard half of them, including some items that were reported to have largest correlations with GPA in the original MSLQ manual. All in all, we find three important issues with the aforementioned methodological practices used when developing and validating MSLQ and other learning strategy inventories.

First, we believe that the described approach to the development of learning strategies

\footnotetext{
${ }^{2}$ By hierarchy we mean any form of a structure "that has at least two levels with a one-to-many mapping of elements in the higher level to elements in the lower level" (Markman, 1999 and Novick \& Hurley, as cited by Logan \& Crump, 2011). This implies that not only higher-order, but also first-order factorial structures are hierarchical in their character.

${ }^{3}$ The MSLQ is more of an exception when compared to other inventories with regard to presenting correlations for individual items.
} 
inventories is severely misguided due to the dominant methodological practice in the mainstream academic psychology and the mainstream scale development literature (for a cogent overview of the misguided practices, see Rossiter, 2011). Namely, we argue that the MSLQ and other inventories of learning strategies cannot be soundly defined and treated as reflective latent structures. In other words, Elaboration, Organization, Resource management and other constructs should not be conceptualized as latent variables (properties, attributes, dispositions) extant in learners and being responsible for tendencies in individual behaviors; if one wants to make a higher-level taxonomy of such constructs they should be conceptualized as formative constructs whose delineating characteristics are completely defined by researchers through their expert knowledge and content similarities among the items. Obviously, if a researcher would be solely interested in modeling individual differences and identifying respective dimensions in learning behaviors (e.g. investigating learning styles) then a reflective model could be an appropriate one. We believe that most researchers and practitioners who want to change how students approach their learning, are more interested in classifying and assessing the benefits of the use of various self-regulated behaviors. To put it simply, the focus should be on the behaviors and not on the learners. This is also partly reflected by naming of the scales in the MSLQ, where names evidently refer to groups of strategies and not properties of learners. In addition, we should not forget that by adopting a reflective model and its widespread methodology one introduces another systematic bias in the extant instruments; the structures of the well-known learning strategy inventories were significantly influenced by researchers' attempts to write down content similar items which would eventually result in sufficient within-scale correlations enabling proper grouping of items and "satisfactory" indices of internal consistency.

Secondly, we believe that by focusing on hierarchically higher constructs - be it of reflective or formative nature - researchers might miss important conclusions about the benefits of using individual learning strategies. For instance, already the data from the MSLQ user manual (Pintrich et al., 1991) provides insight into the significant variability of individual item-grade correlations within the subscales which sometimes speak for important differential effects. In some cases individual items had better predictive validity compared to the subscale scores (see Organization subscale), while in others the 
set of items belonging to the same subscale had opposite predictive signs (e.g. Help seeking behaviors). Interestingly, very recently more focus has been placed on the importance of individual items within the personality inventories with regard to their criterion validity in contrast to the domain or facet levels (Mõttus, 2016; Seeboth \& Mõttus, 2018).

Our final issue with the popular extant inventories of learning strategies is that they do not - adequately or at all - include recent learning opportunities provided by new technologies. For example, those inventories miss to ask learners if they attend massive online open courses (MOOCs), deliberately watch educational video materials posted online, use flash-card applications enabling spaced repetition memorization, or use specialized concept organization applications. We believe that a significant share of learners - especially at the university-level - might effectively use such behaviors while learning.

Therefore, with this study we aimed to develop a content- and criterion-valid contemporary inventory of learning strategies that could be used with both secondary education and higher-education learners. We attempted to encompass as many as possible relevant individual learning behaviors and, by doing so, we were not interested in establishing a clustering/hierarchical structure conceptualized as a latent variable model. Nevertheless, in order to investigate the value of item-level analysis we hypothesized that individual learning strategies would reliably predict the GPA variance and that this prediction would be at least as good as what would be achieved by a reflective, latent variables approach. To test this hypothesis we decided to empirically compare several prediction models: a full set of individual strategies, a set of selected individual strategies, and a set of latent variables which would result from a commonly employed factor analysis.

\section{Methods}

Procedure of item development 
The first step taken when developing our instrument named BLILS (Banja Luka Inventory of Learning Strategies; Lakić, Damjenić, \& Šain, 2015) was to review the extant learning strategies inventories. From the pool of thus collected items we selected those that seemed content-relevant and indicated only one specific learning behavior, i.e. we ensured that the item-targeted behavior was exclusively dedicated to a single indicator. Therefore, a number of original items were combined and reworded, after which we added several items for behaviors that were not included in the extant instruments ${ }^{4}$. The final wording of all items and their intended functioning was checked through cognitive interviews conducted with two students with exceptional academic achievement. The interviewees were further probed to find out whether they used additional strategies in their learning.

The total number of items amounted to 61, out of which 21 items were not considered in this study since they targeted affective-motivational aspects of learning (e.g. self-efficacy beliefs, motivational interventions, procrastination issues, parent pressure). Thus, we were left with 40 proper learning strategy items. Where necessary, we adapted the wording for a high-school context (the master version of the instrument was developed for the university level). The participants were provided with a five-step graded scale (from $0=$ never to $4=$ almost always) to rate how frequently they used a particular learning strategy while studying for school subjects.

\section{Participants}

We collected 402 valid anonymous responses from students attending four different public high-schools in the city of Banja Luka. Gender composition was well-balanced (202 females, $50.2 \%$ of the total sample) and $96.2 \%$ of students were either 16 or 17 years old. In addition to responding to the BLILS, the participants provided a number of demographic and school-related data (e.g. GPA). The principals of the schools gave their approval to conduct the study.

\footnotetext{
${ }^{4}$ In this process we were primarily inspired by the MSLQ, which is an instrument in the public domain. We should, however, state that we followed all principles of the fair use of intellectual property and that none of the items were intended to be verbatim copied.
} 


\section{Data analysis}

We used descriptive statistics to explore responses on individual items. Exploratory factor analysis (principal axis with oblique rotation) was used to explore a factorial structure on the matrix of item intercorrelations (polychoric coefficients). The associations among the items, factor scores and GPA were analyzed using correlational analysis and multiple regressions. To analyze data we used freely available software JASP 0.8.4 (JASP Team, 2018) and R version 3.3.3 (R Core Team, 2017) with packages psych (Revelle, 2017) and multicon (Sherman, 2015).

\section{Results}

To acquaint a reader with the BLILS content, we first show the most and the least reported learning strategies. Then, we show the predictiveness of a model with all items included, followed by a model with only selected items. Next, we conduct an exploratory factor analysis used to extract latent variable solutions. Finally, we directly compare all identified models with respect to their predictive validity.

\section{The frequency of using individual learning strategies}

Table 1 presents five most frequently used learning strategies, whereas Table 2 presents five learning strategies that were the least reported in our sample. The list of the most frequently reported learning strategies contains some behaviors that are known to be popular among the students (e.g. re-reading study materials, rehearsing, see e.g. Pintrich et al., 1991). On the other side, among the least reported ones are those related to peerlearning, using flashcards, attending online courses, and using audio recordings - all those behaviors that we would expect to be more frequently used by students at a higher, university level of education. Importantly, we observed that all response options were endorsed by students, regardless of the relative difficulty of the items.

(INSERT TABLE 1 AND TABLE 2 HERE)

\section{Table 1}


The most frequently reported BLILS items

\begin{tabular}{|c|c|c|c|c|}
\hline Items & $M$ & $S D$ & Min & $\operatorname{Max}$ \\
\hline $\begin{array}{l}\text { Only when I am sure that I understood all parts of } \\
\text { the materials I read, I move on to study another } \\
\text { material. }\end{array}$ & 3.00 & 1.18 & 0 & 4 \\
\hline $\begin{array}{l}\text { After I finished learning a part, I rehearse (either } \\
\text { aloud or silently) in order to evaluate how well I } \\
\text { learned the material. }\end{array}$ & 2.86 & 1.32 & 0 & 4 \\
\hline I study in silence. & 2.87 & 1.29 & 0 & 4 \\
\hline $\begin{array}{l}\text { When studying, I evaluate how well I adopted the } \\
\text { material I learned }\end{array}$ & 2.86 & 1.22 & 0 & 4 \\
\hline I learn by re-reading study materials several times & 2.74 & 1.21 & 0 & 4 \\
\hline
\end{tabular}

Table 2

The least frequently reported BLILS items

\begin{tabular}{|c|c|c|c|c|}
\hline Items & $M$ & $S D$ & Min & $\operatorname{Max}$ \\
\hline $\begin{array}{l}\text { I study together with my classmates when we } \\
\text { question each other. }\end{array}$ & 0.72 & 1.06 & 0 & 4 \\
\hline I study with my radio turned on. & 0.71 & 1.19 & 0 & 4 \\
\hline $\begin{array}{l}\text { I memorize keywords by using flashcards which } \\
\text { have a term defined on the opposite side. }\end{array}$ & 0.49 & 0.93 & 0 & 4 \\
\hline I attend online courses (e.g. Coursera, EdX, & & & & \\
\hline $\begin{array}{l}\text { Udacity) related to the subjects I attend this } \\
\text { school year. }\end{array}$ & 0.36 & 0.89 & 0 & 4 \\
\hline $\begin{array}{l}\text { I make audio recordings of lectures and I listen to } \\
\text { those afterwards. }\end{array}$ & 0.21 & 0.72 & 0 & 4 \\
\hline
\end{tabular}


Individual learning strategies as predictors of GPA

The full model composed of all 40 items as predictors accounted for the exceptional amount of the GPA variance $\left(R^{2}=.39\right.$, adjusted $\left.R^{2}=.32, F(40,358)=5.73, p<.001\right)$. Nevertheless, it is well-known that the sheer number of predictors is on its own an extraneous factor in explaining the variance of a criterion, contributing to the phenomenon of overfitting (Babyak, 2004; Freedman, 1983). In order to control for overfitting conclusions we decided to randomly divide our sample into two equal subsamples of $n=201$, after which we decided on a minimum value of a correlation to serve as a cutoff value for a predictor to be considered in future analysis. Such a sample splitting procedure is a simple and recommended procedure for model validation (Good \& Hardin, 2009, pp. 214-215). When it comes to a specific measure to be considered as an evidence of statistical stability, we opted for a Bayes factor $\left(B F_{10}\right)$ of 3.0 against the point null hypothesis with noninformative stretched beta prior of 1 (Wetzels \& Wagenmakers, 2012). This value equaled to the absolute value of sample correlation of $\mid r$ $=.188$, with alpha values for statistical significance being exactly $p=.01$ and with $95 \%$ credible intervals having a lower bound of at least $|r|=.05$. In other words, only those items whose correlations on both subsamples were equal or larger to .19 $(|r| \geq .19, p<$ .01) were included in the final model. Naturally, by using this strategy we limited a number of potentially important individual strategies, but we remind the reader that the very purpose of this part of our study was to compare the predictabilities of differently derived models and not to identify all effective learning strategies.

Following the aforementioned procedure, we observed 11 items having correlations with GPA larger than the cutoff level in both subsets. After we combined the subsets, the minimum zero-order correlation obtained was $r(400)=.21$, CI $[.11, .30], B F_{10}=494.1$, thus showing the high support for systematic associations among these individual behaviors and GPA. Moreover, the model composed of 11 predictors explained a substantial portion of the variance both in the subsamples (sample $1: R^{2}=.37$, adjusted $R^{2}=.33$; sample 2: $R^{2}=.30$, adjusted $\left.R^{2}=.26\right)$ and when those were combined $\left(R^{2}=.31\right.$, adjusted $\left.R^{2}=.29\right)$ with all $P$-values for the tested models being smaller than .001 . Table 
3 shows the zero-ordered correlation coefficients, as well as standardized regression coefficients and squared semi-partial correlations within the total sample. The sum of squared semi-partial correlations indicates that around $14 \%$ of the variance GPA shares only with specific items, while the rest of it (17\%) can be attributed to common variance shared among the items.

(INSERT TABLE 3 AROUND HERE)

Table 3

BLILS items selected through cross-validation correlational analysis

\begin{tabular}{llllllll}
\hline Items & $r$ & $r_{1}$ & $r_{2}$ & $s r^{2}$ & $\beta$
\end{tabular}

When I need to learn a list of concepts, I make my own associations in order to memorize them more easily (e.g. I make acronyms, I visualize a relationship)

$\begin{array}{lllll}.32 & .42 & .23 & .01 & .12\end{array}$

While studying, I evaluate how well I adopted the material I learned

$\begin{array}{lllll}.21 & .21 & .23 & .00 & .00\end{array}$

I precisely plan periods of time and/or the amount of materials I will learn during one session of learning

$\begin{array}{lllll}.22 & .24 & .22 & .00 \quad .05\end{array}$

I study regularly throughout the school year, and not only before tests.

$\begin{array}{lllll}.33 & .36 & .29 & .01 & .15\end{array}$

After I complete a study session, I evaluate how much I achieved in comparison to what I planned

$\begin{array}{lllll}.26 & .29 & .24 & .00 & .05\end{array}$

If there is a shortened summary of a text I mostly learn from it

$\begin{array}{lllll}-.24 & -.19 & -.29 & .03 & -.17\end{array}$

When I learn I also use textbooks and other texts not belonging to assigned readings (note: shortened summaries are not considered here)

$\begin{array}{lllll}.24 & .20 & .26 & .00 & .05\end{array}$

I try to learn by memorizing by heart

$\begin{array}{lllll}-.21 & -.22 & -.19 & .06 & -.26\end{array}$

In class, I ask a teacher to clarify things I don't understand well 
In class, I take notes

I learn by using other digital materials which do not belong to assigned learning materials (e.g. software, educational websites, blogs, video materials)

Note. $r_{1}$ and $r_{2}$ denote correlations on two data subsets $(\mathrm{n}=201$ each $) ; s r^{2}=$ squared semi-partial correlation.

\section{Exploratory factor analysis of the BLILS}

In order to mimic the usual procedure of developing reflectively based measures, we conducted an exploratory factor analysis on the whole sample. Since the responses were given on ordinal categorical scales with many items having markedly asymmetric distribution which might spuriously influence the factor solution, we decided to conduct the analysis on a matrix of polychoric correlations (see Holgado-Tello, ChacónMoscoso, Barbero-García, \& Vila-Abad, 2008, Timmerman \& Lorenzo-Seva, 2011, and Yang \& Xia, 2015 for a discussion on advantages of using polychoric correlations). The important decision researchers need to make is to decide on the number of significant latent variables to be retained in the analysis, since those provide an evidence of construct validity for the scales they want to develop. Although the experts did not come to an unambiguous solution of this problem, parallel factor analysis has been championed as an optimal empirical solution in many simulations conducted (Cho, Li, \& Bandalos, 2009; Crawford et al., 2010; Timmerman \& Lorenzo-Seva, 2011; Yang \& Xia, 2015). At the same time there are sensible arguments to consult scree plots, particularly when the solution suggested by parallel analysis does not show a conspicuous pattern (Steger, 2006; Zwick \& Velicer, 1986). Indeed, parallel factor analysis on polychoric correlations suggested to retain 7 common factors, while at the same time we observed three factors with distinctly elevated eigenvalues on a scree plot (see Figure 1). We decided to extract both the seven-factor and three-factor solution in order to satisfy both approaches when deciding on a number of latent variables, and having in mind that a recent paper (Hilpert et al., 2013) suggested a greatly simplified structure of the MSLQ by retaining only three factors. 


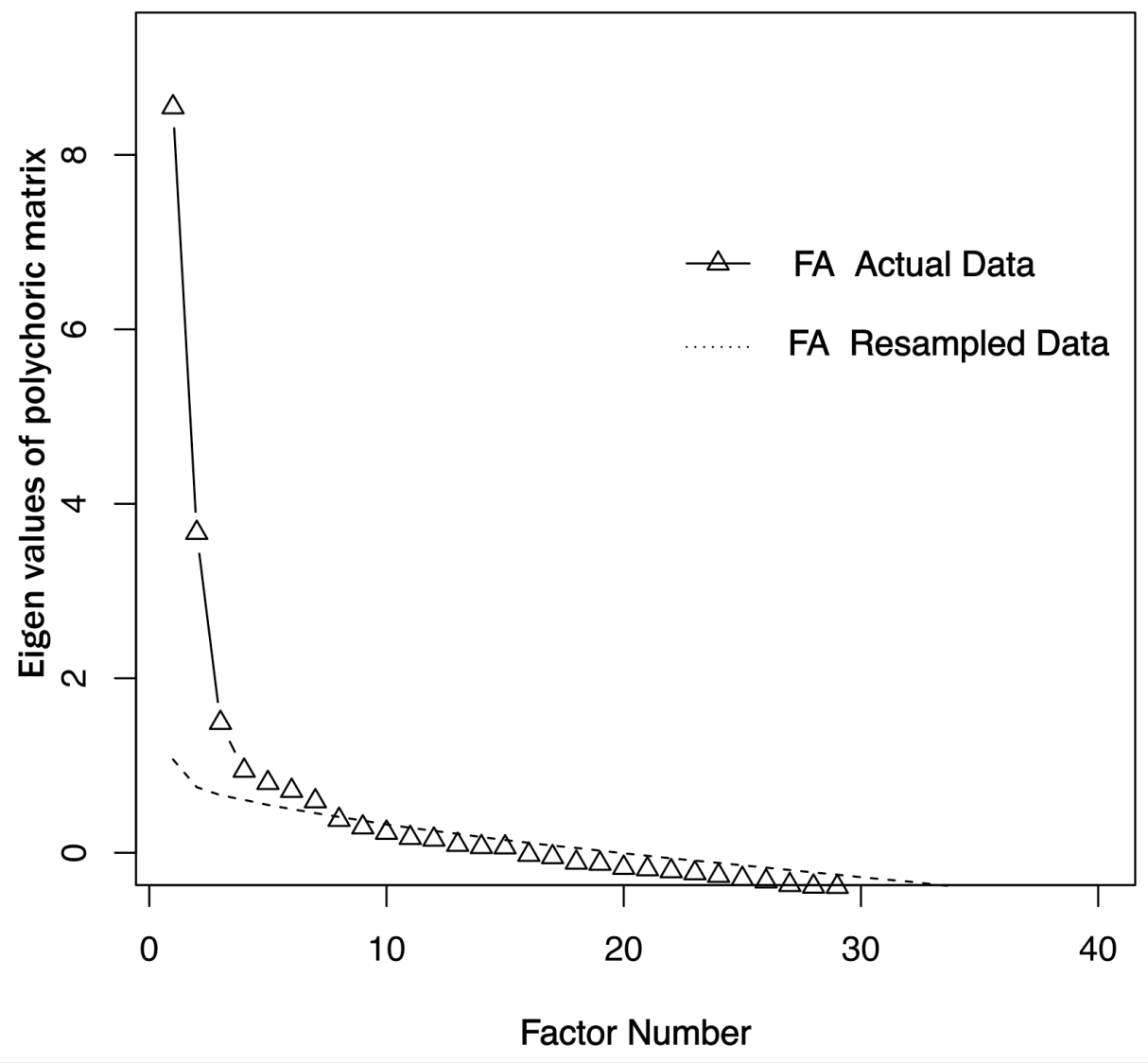

Figure 1. Scree plot of parallel factor analysis on polychoric matrix of correlations.

The three-factor solution explained $36.0 \%$ of the common variance of learning strategies. The first factor - General self-regulated learning - was mainly defined by metacognitive activities (planning, monitoring and rehearsal-related evaluating), but it also included marker variables from other conceptual domains (e.g. elaboration through making own mnemonics or visualization techniques). The second factor - Supplemental learning strategies - saturated less frequently reported learning activities, which comprised Elaboration (attending online courses, reading additional texts), Monitoring (keeping a written learning $\log$ ), Retention strategies (using flashcards) and Social learning behaviors (learning together with peers). Finally, the third factor - Controlling sonic 
environment - was defined by items related to the use of external sounds when learning (positively: learning in silence positively, and negatively: with selected music on, with radio on, with TV on). Interestingly, we observed moderate positive correlations between GPA and General self-regulated learning $(r=.36, p<.001)$ and Controlling sonic environment $(r=.25, p<.001)$, whereas Supplemental learning activities did not correlate with GPA at all $(r=-.03, p=.53)$. Additional inspection showed the evidence for the differential effect of 11 individual learning strategies representing the supplemental strategies; namely, some of them correlated positively with the GPA (reading additional materials, peer-learning, keeping a learning log) while three of them correlated significantly negatively (speed reading, learning from shortened summary texts prepared by former cohorts of students, verbatim rehearsal).

Obviously, a seven-factor solution provided a more complex picture. Since the purpose of the study was not to explore this factor structure in detail we give here only a short description of the factors, starting with their labels based on the item content: Metacognitive strategies, Organizing strategies, Rehearsal and understanding, Seeking help from teachers, Controlling sonic environment, Memorizing and speed-learning, Learning from shortened summaries. The highest correlations among the factors were below .50 (the two largest ones were .46 and .44), thus all identified factors were distinct from a statistical viewpoint. That said, some factors either had only two marker variables with high factor loadings or their composition varied significantly content-wise, making it hard to interpret them theoretically as proper latent variables. Having these issues in mind, we decided to operationalize the identified variables as factor scores rather than using sum scores.

Comparing criterion validity of individual learning strategies against reflectively derived measures

By using multiple regressions ${ }^{5}$ with relevant criteria (amount of shared variance, difference between the sample and expected population amount of shared variance,

\footnotetext{
${ }^{5}$ We checked for multicollinearity, outliers and heteroscedasticity, and found no violation of assumptions for conducting multiple regressions.
} 
Akaike information criterion), we compared the criterion validity of four different models we considered in this study. As Table 4 shows, the full model containing all individual strategies still shared the largest amount of variance with GPA. For the reasons already mentioned (overfitting) and considering the AIC values, either a model with 11 individual learning strategies or the seven-factor model should be preferred if there were a need to select only one among them. There was, indeed, a rather negligible difference in predictiveness between these two models; however, apart from the aforementioned theoretical issues with the seven-factor solution, the facts that two out of seven scales did not correlate with GPA at all, and that one would need to have all 40 items (and possibly more in order to develop scales which would satisfy traditional psychometric recommendations) to calculate the proper sum scores, speak for the 11 individual learning strategies. Finally, the three-factor solution shared noticeably less variance with GPA compared to other models.

\section{(INSERT TABLE 4 HERE)}

Table 4

Comparing regression models

\begin{tabular}{|c|c|c|c|c|}
\hline Model & $R^{2}$ & $\begin{array}{c}\text { Adjusted } \\
R^{2}\end{array}$ & $A I C$ & $p$ \\
\hline All individual strategies & .390 & .322 & 812.4 & $<.001$ \\
\hline Selected individual strategies & .310 & .291 & 808.3 & $<.001$ \\
\hline 3-factor model & .226 & .220 & 833.4 & $<.001$ \\
\hline 7-factor model & .287 & .274 & 808.9 & $<.001$ \\
\hline
\end{tabular}

\section{Discussion}

The purpose of this study was twofold. First, we wanted to develop and empirically test a new instrument for assessing students' use of learning strategies. Secondly, and more 
generally, we wanted to question how justified it is to continue applying dominant and widely recommended psychometric procedures when developing not only learning strategies inventories, but also psychological measures overall. In contrast to what is usually done when pursuing such goals, to a large degree we disregarded construct validation procedures, and instead, we concentrated on content and criterion aspects of validity. We believe that the results shown lend support to our premises: that the BLILS is a promising inventory of learning strategies and that more attention should be given to alternatives to reflective, latent variables models, at least in this domain.

One of the strongest arguments for the BLILS adequacy is its criterion validity with the large amount of variance explained through each model tested $\left(R_{\min }^{2}=.22\right)$, which was accompanied with the finding that a number of individual study behaviors correlated notably with GPA. Specifically, for 18 out of 40 items we observed correlations larger than .15 , while there were 24 items with correlations larger than $.10^{6}$. Although done at the university level, the findings of the meta-analytic studies by Richardson, Abraham and Bond (2012) and Crede and Phillips (2011) might serve as a coarse comparison to $\mathrm{MSLQ}^{7}$ : the estimated parameters of correlations of proper learning strategies scales with GPA was at maximum .23, with most of the correlations being between .10 and .20 . In other words, the magnitude of effects of individual BLILS items equals or surpasses the effects of related composite scales of learning strategies within the MSLQ.

Aside from its criterion validity, we believe there are other desirable features of our inventory. For example, we included behaviors related to using new technologies, while still keeping the number of items less than some other inventories (e.g. 40 compared to 50 or more items related to proper learning strategies in MSLQ). This was also made possible by choosing not to develop internally consistent (sub)scales. To create an adequately internally consistent scale, an author needs to formulate several items with similar, partially overlapping content, rather than cover it with a single item where

\footnotetext{
6 These are the results for the linear correlation coefficients, while one could expect even larger estimates if we used polyserial correlations since item-levels are ordinal categorical variables.

${ }^{7}$ Unfortunately, to our knowledge no similar studies were conducted to explore the effects of learning strategies on GPA at the secondary education level. Indeed, the level of educational setting could be regarded as a potential moderator; therefore, this comparison should be taken with caution.
} 
possible. In addition, we ensured that all of BLILS items were worded in positive direction (i.e. without using negations). We also opted for a five-point response scale where each option was labeled, substantively suitable, and easy to understand (from "never" to "almost always"). These two decisions should have led to higher validity of responses. Finally, it is interesting to note that all options on all items were chosen which indirectly speaks for the appropriateness of the response scales.

In spite of the positive qualities mentioned, we are aware that there is a legitimate question of how to use our instrument without having a smaller number of variables to operate with. We argue that the BLILS should be used both as a research and diagnostic tool by solely concentrating on individual items and not calculating sum scores (although there is a possibility to use factor analytic solutions). Understandably, a larger number of units to analyze makes a work more complex and time-demanding; nevertheless, we showed that one could select a smaller number of particularly effective strategies and to concentrate only on those. Before doing that, it would be well-advised to replicate our findings on a sample that is related to the population of interest. Although using individual items obviously asks for more effort from a researcher, we believe that benefits outweigh the costs. There are evidences that this is true for other aspects of psychological assessment, especially when criterion validity is of the utmost importance; the most representative examples of switching focus to hierarchically lowest levels are recent modeling of the importance of individual items in personality inventories (Brown \& Sherman, 2014; Mõttus, Kandler, Bleidorn, Riemann, \& McCrae, 2017; Seeboth \& Mõttus, 2018).

We are aware of several limitations of our study, which also limit our conclusions about the BLILS. For instance, we show here only the results on the sample of high school students. We cannot estimate to what degree the level of education moderates not only the use of individual strategies, but also their effectiveness. We are currently in the process of collecting data on university students, and hopefully, we will have some answers soon. Secondly, we surveyed average tendencies in learning across different subjects and used GPA as the only criterion of school achievement. It is obvious that different school subjects assume different learning outcomes composed of knowledge, 
skills and attitudes; thus, it is very plausible that the type of a subject should have a moderating role on the effectiveness of the strategies. In future studies it would be possible to explore the functionality of different strategies within various subjects, for which individual subject grades or standardized test scores could be used as criteria. Overall, this lack of referential values across different contexts will hinder the use of the BLILS for diagnostic purposes. To obtain these we will need to combine a series of studies in various contexts. The practitioners should also have in mind that many items might have a satisfactory match in items from other inventories, so in theory it would be possible to retrieve information from earlier studies. That said, our claims about the strength of criterion validity of the BLILS are limited, since we did not simultaneously administer other inventories to compare that empirically.

To conclude, we see this paper as a contribution to the state of affairs in exploring learning strategies. We believe that the BLILS covers well the content domain of contemporary learning strategies, and represents a promising instrument both for researchers and practitioners. Our results are obtained on a moderately large sample, which could be considered as representative enough for high school students in the region. Moreover, we hope that this paper will turn readers' attention to the issue of uncritical applying of dominant psychometric procedures on psychological and educational phenomena. Specifically, we advise readers to always critically assess whether latent variable model is justified in the first place, and we - together with recent calls from other researchers (e.g. Mõttus, 2016) - advise them to place more value on individual items, not only in this domain of research, but in others as well.

\section{REFERENCES}

Babyak, M. A. (2004). What You See May Not be What You Get: A Brief Introduction to Overfitting. Psychosomatic Medicine, 66, 411-421. Retrieved from http://www.vicc.org/biostatistics/2010workshop/Overfitting_0416.pdf

Biggs, J., Kember, D., \& Leung, D.Y.P. (2001). The revised two-factor Study Process Questionnaire: R-SPQ-2F. British Journal of Educational Psychology, 71, 133-149. 
Brown, N. A., \& Sherman, R. A. (2014). Predicting interpersonal behavior using the Inventory of Individual Differences in the Lexicon (IIDL). Journal of Research in Personality, 51, 23-28.

Cho, S.-J., Li, F., \& Bandalos, D. (2009). Accuracy of the Parallel Analysis. Educational and Psychological Measurement, 69(1670), 748-759.

Crawford, A. V., Green, S. B., Levy, R., Lo, W.-J., Scott, L., Svetina, D., \& Thompson, M. S. (2010). Evaluation of Parallel Analysis Methods for Determining the Number of Factors. Educational and Psychological Measurement, 70(6), 885-901. https://doi.org/10.1177/0013164410379332

Crede, M., \& Kuncel, N. R. (2008). Study Habits, Skills, and Attitudes. Perspectives on Psychological Science, 3(6), 425-454.

Credé, M., \& Phillips, L. A. (2011). A meta-analytic review of the Motivated Strategies for Learning Questionnaire. Learning and Individual Differences, 21(4), 337-346. https://doi.org/10.1016/j.lindif.2011.03.002

de Boer, H., Donker-Bergstra, A. S., \& Kostons, D. D. N. M. (2012). Effective Strategies for Self-regulated Learning: A Meta-Analysis. GION, Gronings Instituut voor Onderzoek van Onderwijs, Rijksuniversiteit Groningen No.

Dunn, K. E., Lo, W. J., Mulvenon, S. W., \& Sutcliffe, R. (2012). Revisiting the Motivated Strategies for Learning Questionnaire: A Theoretical and Statistical Reevaluation of the Metacognitive Self-Regulation and Effort Regulation Subscales. Educational and Psychological Measurement, 72(2), 312-331. https://doi.org/10.1177/0013164411413461

Freedman, D. A. (1983). A note on screening regression equations. American Statistician, 37(2), 152-155. https://doi.org/10.1080/00031305.1983.10482729

Good, P. I., \& Hardin, J. W. (2009). Common errors in statistics (and how to avoid them). John Wiley $\backslash \&$ Sons. 
Hilpert, J. C., Stempien, J., van der Hoeven Kraft, K. J., \& Husman, J. (2013). Evidence for the Latent Factor Structure of the MSLQ: A New Conceptualization of an Established Questionnaire. SAGE Open, 1-10. https://doi.org/10.1177/2158244013510305

Holgado-Tello, F. P., Chacón-Moscoso, S., Barbero-García, I., \& Vila-Abad, E. (2008). Polychoric versus Pearson correlations in exploratory and confirmatory factor analysis of ordinal variables. Quality \& Quantity, 44(1), 153-166. https://doi.org/10.1007/s11135-008-9190-y

JASP Team (2018). JASP(Version 0.8.4) [Computer software]

Lakić, S., Damjenić, M. i Šain, D. (2015). Banja Luka Inventory of Learning Strategies. Banja Luka: Faculty of Philosophy, University of Banja Luka.

Logan G. D. \& Crump, M. J. C. (2011). Hierarchical Control of Cognitive Processes: The Case for Skilled Typewriting. In B. H. Ross (Ed.), The Psychology of Learning and Motivation: Advances in Research and Theory (pp. 1-27). Burlington: Academic Press.

Mõttus, R. (2016). Item-Level Analyses Should Become Standard - For More than One Reason. European Journal of Personality, 30, 304-340.

Mõttus, R., Kandler, C., Bleidorn, W., Riemann, R., \& McCrae, R. R. (2017). Personality Traits Below Facets: The Consensual Validity, Longitudinal Stability, Heritability, and Utility of Personality Nuances. Journal of Personality and Social Psychology, 112(3), 474-490. https://doi.org/10.1037/pspp0000100

Pintrich, P. R., Smith, D. a. F., Garcia, T., \& McKeachie, W. J. (1993). Reliability and Predictive Validity of the Motivated Strategies for Learning Questionnaire (MSLQ). Educational and Psychological Measurement, 53(3), 801-813. https://doi.org/10.1177/0013164493053003024

Pintrich, P., Smith, D. A., Garcia, T., \& McKeachie, W. J. (1991). A manual for the use of the Motivated Strategies for Learning Questionnaire (MSLQ). Retrieved from 
http://www.eric.ed.gov/ERICWebPortal/recordDetail?accno=ED338122

R Core Team (2017). R: A language and environment for statistical computing. R Foundation for Statistical Computing, Vienna, Austria. URL https://www.Rproject.org/.

Revelle, W. (2017) psych: Procedures for Personality and Psychological Research, Northwestern University, Evanston, Illinois, USA, https://CRAN.Rproject.org $/$ package $=$ psych Version $=1.7 .8$.

Richardson, M., Abraham, C., \& Bond, R. (2012). Psychological correlates of university students' academic performance: a systematic review and meta-analysis. Psychological Bulletin, 138(2), 353-87. https://doi.org/10.1037/a0026838

Rossiter, J. R. (2011). Marketing measurement revolution: the C-OAR-SE method and why it must replace psychometrics. European Journal of Marketing, 45, 1561-1588.

Schellings, G. (2011). Applying learning strategy questionnaires: Problems and possibilities. Metacognition and Learning, 6(2), 91-109. https://doi.org/10.1007/s11409-011-9069-5

Seeboth, A., \& Mõttus, R. (2018). Successful explanations start with accurate descriptions: Questionnaire items as personality markers for more accurate prediction and mapping of life outcomes. Journal of Personality. https://doi.org/10.17605/OSF.IO/U65GB

Sherman, R. A. (2015). multicon: Multivariate Constructs. R package version 1.6. https://CRAN.R-project.org/package=multiconmulticon

Steger, M. F. (2006). An illustration of issues in factor extraction and identification of dimensionality in psychological assessment data. Journal of Personality Assessment, 86(3), 263-72. https://doi.org/10.1207/s15327752jpa8603_03

Timmerman, M. E., \& Lorenzo-Seva, U. (2011). Dimensionality assessment of ordered polytomous items with parallel analysis. Psychological Methods, 16(2), 209-20. 
https://doi.org/10.1037/a0023353

Vermunt, J. D. (1994). Inventory of learning styles in higher education. Tilburg: Tilburg University, Department of Educational Psychology.

Weinstein, C.E., Palmer, D.R., \& Schulte, A.E. (2002). Learning and Study Strategies Inventory (LASSI) 2nd ed. Clearwater, Florida: HandH Publishing Company, Inc.

Weinstein, C. E., Schulte, A., \& Palmer, D. R. (1987). The Learning and Study Strategies Inventory. Clearwater, FL: $\mathrm{H} \& \mathrm{H}$ Publishing.

Wetzels, R., \& Wagenmakers, E.-J. (2012). A default Bayesian hypothesis test for correlations and partial correlations. Psychonomic Bulletin \& Review, 19, 10571064. https://doi.org/10.3758/s13423-012-0295-x

Yang, Y., \& Xia, Y. (2015). On the number of factors to retain in exploratory factor analysis for ordered categorical data. Behavioural Research, 47, 756-772. https://doi.org/10.3758/s13428-014-0499-2

Zwick, W. R., \& Velicer, W. F. (1986). Comparison of five rules for determining the number of components to retain. Psychological Bulletin, 99(3), 432-442.

https://doi.org/10.1037//0033-2909.99.3.432 